\title{
Correction to: Lexical processes in the recognition of Japanese horizontal and vertical compounds
}

\author{
Koji Miwa ${ }^{1}$ D $\cdot$ Ton Dijkstra²
}

Published online: 11 October 2018

(c) Springer Nature B.V. 2018

\section{Correction to: Read Writ (2017) 30:791-812 https://doi.org/10.1007/s11145-016-9700-6}

The original publication of the article contained an error. In Figure 3, the y-axis label for Panel (e) should be "Saccade Velocity (degrees/sec)"; it is not "Second Fixation Duration (ms)." Below is the corrected version of Fig. 3.

The original article can be found online at https://doi.org/10.1007/s11145-016-9700-6.

Koji Miwa

kojimiwa4@gmail.com

1 Seminar für Sprachwissenschaft, Eberhard Karls Universität Tübingen, Wilhelmstraße 19, Raum 3.22, 72074 Tübingen, Germany

2 Donders Institute for Brain, Cognition, and Behaviour, Radboud University Nijmegen, Nijmegen, The Netherlands 
(a)

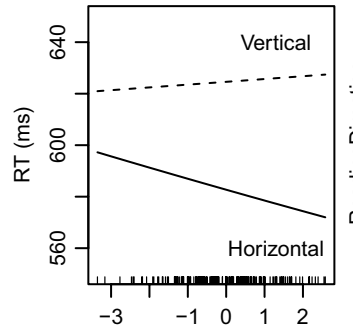

FirstCharacterFrequency (b)

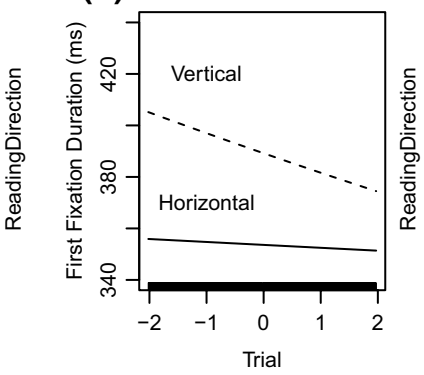

(e)
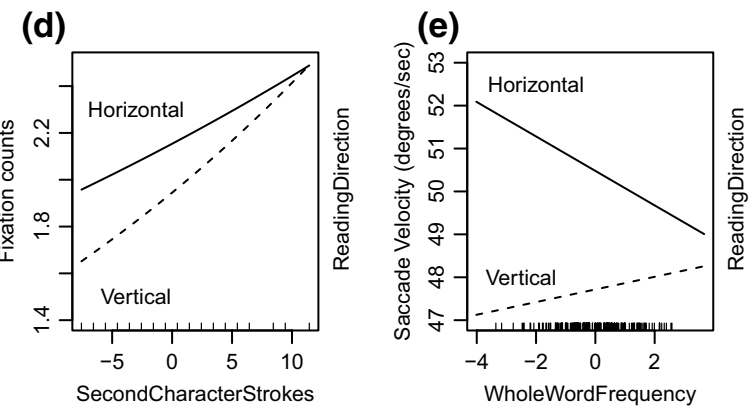

(c)

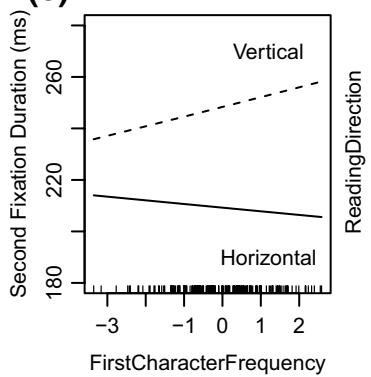

Fig. 3 Interactions between lexical predictors and reading direction observed in the mixed-effects model for response times, first fixation durations, second fixation durations, fixation count, and saccade velocity. Note: The rugs reflect a distribution of the predictor values 